\title{
LÓPEZ FÉREZ, Juan Antonio, Teorías de Galeno sobre el semen feme- nino, México, Universidad Nacional Autónoma de México, 2015 (Supplementum VIII. Nova Tellus), 102 págs.
}

El estudio que nos ocupa se abre con una dedicatoria al patricio venezolano Blas Bruni Celli, señalado en muchos aspectos, y entre ellos el de la promoción de la medicina griega. Al autor del trabajo se deben numerosas contribuciones al conocimiento del drama griego y en especial de Eurípides, al de la medicina hipocrática y galénica, al de la mitología y al de la recepción de la literatura griega en la española, entre otros campos donde nuestro helenista es competente. Pero hay que saludar la aparición de monografías como la presente por la significación que tienen para la difusión de la investigación. Resulta de la mayor importancia el procedimiento de análisis puesto en práctica por López Férez, basado en la aplicación del método filológico y en la fijación de una traducción literal, contrastada y sumamente precisa (tómese como referencia cuanto se dice en p. 79, n. 245, sobre el verbo ỏoyó $(\omega)$. Añádase el interés que en todo momento muestra el especialista por el origen, significación y evolución semántica y morfológica de los términos técnicos propios de la lengua médica de Galeno, que por sí mismo integra un capítulo riquísimo y de gran utilidad para historiadores de la medicina, estudiosos de las lenguas profesionales y filólogos.

La presente reseña representa uno de esos casos donde la obra sometida a juicio no deja margen alguno para que redarguyamos ninguno de sus elementos básicos, ni en su metodología, ni en su estructura, ni en sus contenidos, ni en sus resultados. A nuestro alcance está sólo señalar la relevancia del trabajo para la investigación contemporánea y futura, y reseñar si procede matices interpretativos que ayuden a completar la operación her-

PALABRAS Clave: Galeno; ginecología; medicina; semen.

KEYwORDS: Galen; Gynecology; Medicine; Semen.

RECIBIDO: 13 de marzo de 2017 - ACEPTADO: 1 de junio de 2017.

DOI: 10.19130/iifl.nt.2017.35.1.759 
menéutica de la embriología galénica. $\mathrm{Al}$ respecto, conviene apreciar en su justo valor el esfuerzo y los logros de López Férez en un dominio, el de los estudios ginecológicos dentro de la medicina antigua, en el que no abundan las monografías. ${ }^{1}$ Las novedades metodológicas introducidas por el especialista consisten, por un lado, en el tratamiento filológico de las fuentes, consideradas de manera omnicomprensiva y exhaustiva, a diferencia de aquellas monografías que no hacen del análisis textual el principal instrumento de interpretación; por otro, la acotación de la materia médica, en este caso la ginecología, a un tema muy concreto, el de la secreción seminal. Conste además que el estudioso no había abordado de manera específica el tema en sus anteriores trabajos sobre asuntos ginecológicos. ${ }^{2}$

El estado de la cuestión no habría de reducirse a la breve descalificación de Moore, ${ }^{3}$ pero es cierto que hasta ahora no se había reconocido la trascendencia de la aportación de Galeno. ${ }^{4}$ De la mano de la pormenorizada explicación facilitada por López Férez, vemos que son varias las características relevantes de la teoría galénica sobre la procreación que hacen de ella un hito de especial relevancia en la materia ginecológica. No nos referiremos aquí a la autopsía y al empirismo como bases metodológicas de la ciencia del de Pérgamo, ni a la exhaustividad, el rigor y la capacidad didáctica con los que Galeno atacó siempre cualquier cuestión médica; queremos en cambio subrayar la perspectiva multidisciplinar adoptada por nuestro autor

\footnotetext{
${ }^{1}$ Junto a los ya antiguos trabajos de J. Lachs, Die Gynaekologie des Galens. Eine geschichtlich-gynaekologische Studie, Breslau, 1903; H. Blass, "Die Zeugungslehre und Embryologie in der Antike. Eine Übersicht”, QGMed, 5, 1936, pp. 1-82 - artículo que por su extensión merece ser incluido entre las monografías-; W. Hedicke, Die Gedanken der Griechen über Familienherkunft und Vererbung, Halle, 1936; K. Blersch, Wesen und Entstehung des Sexus im Denken der Antike, Stuttgart \& Berlin, 1937, y E. Lesky, Die Zeugungs- und Vererbungslehren der Antike und ihr Nachwirken, Wiesbaden, 1950, han de citarse los más recientes de D. Nickel, Untersuchungen zur Embryologie Galens, Berlin, 1989, y L. A. Dean Jones, Women's Bodies in Classical Greek Science, Oxford, 2004.

${ }^{2}$ J. A. López Férez, "Algunos datos sobre la influencia de la teoría embriológica de Demócrito en el Corpus Hippocraticum. Gemelos y abortos", Asclepio, 33, 1981, pp. 379-390; "Ideas embriológicas de Demócrito", Asclepio, 34, 1982, pp. 317-326.

3 J. A. Moore, "Science as a Way of Knowing - Developmental Biology", American Zoologist, 27, 1987, pp. 415-573, p. 428: "He was interested mainly in human anatomy and physiology but he did have a few things about development. [...] He added little to Aristotle's work".

${ }^{4}$ D. Nickel, op. cit., p. 43: "Daß diese Überlegung ebenfalls keines eigenständigen Beitrag des Pergameners zu der Diskussion über die Frage nach dem wiblichen Sperma darstellte, zeigt sich in den Definitiones Medicae, in denen die Ähnlichkeit der Kindern mit den Mütterm als 'der wichstigte Beweis' für die Spermaproduktion beim weiblichen Geschlecht angeführt wurde".
} 
cuando considera desde diversos ángulos lo que para otros podrían ser simples problemas científicos, así como su objetividad. Es así como hay que entender la claridad con la que Galeno expone que en la procreación no sólo interviene un componente genético aportado por vía materna, frente a autores como Aristóteles, Herófilo y Ateneo, sino también que tiene en ella más parte la madre que el padre (p. 40; cf. también p. 52 y n. 122).

Al lado de estos aspectos innovadores de la ciencia galénica, que la sitúan en una línea próxima a la de la medicina moderna, en otros campos el autor se muestra deudor aún de prejuicios precientíficos, como en lo tocante a la formación del feto según su género (p. 41) o a la naturaleza de la fisiología femenina (p. 59). A la mayoría de estos prejuicios, subyace una tradición muy presente en los filósofos presocráticos. Por otra parte, llama la atención en el Pseudo-Galeno la relación entre el atomismo y la teoría embriológica (p. 19). López Férez hace también atinadas observaciones sobre las contradicciones entre la obra aristotélica y el libro décimo de la Historia animalium del Estagirita, considerado espurio (p. 50, n. 118).

Pocos son, en fin, los pasajes donde habría sido útil alguna precisión

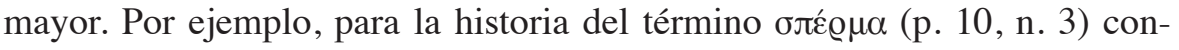
vendría recordar que, como establece María Teresa Gallego, en la colección hipocrática funciona más frecuentemente como tecnicismo de la botánica, lo que obliga a emplear una segunda traducción cuando se aplica a la fisiología humana. ${ }^{5}$

La selección bibliográfica resulta impresionante, y se explica sólo después de toda una trayectoria investigadora. Lo fácil aquí es apuntar algún título de interés, lo difícil señalar una carencia. Para la oposición entre diestro y siniestro puede recordarse la monografía del malogrado Hertz; ${ }^{6}$ en general, sobre la recepción griega de la embriología indoeuropea - por supuesto entendida como pre-ciencia-, véase el trabajo de Bernier. ${ }^{7}$

\footnotetext{
${ }^{5}$ M. T. Gallego Pérez, Vida y muerte en el Corpus Hippocraticum, Madrid, 2015, p. 409: "se atribuye, especialmente, a la simiente de plantas". La coincidencia en la edición de los libros de Gallego y López Férez explica tal vez la paradoja de que aludan de manera independiente a unos mismos problemas de la medicina antigua.

${ }^{6}$ R. W. Hertz, "La prééminence de la main droite: étude sur la polarité religieuse", Revue Philosophique, 34, 1909, pp. 553-580 (= Sociologie religieuse et folklore, París, 1928, pp. 99-129).

${ }^{7}$ R. Bernier, "Étude comparative de l'embryologie hippocratique et de l'embryologie indienne antique", in J. A. López Férez (ed.), Tratados Hipocráticos. Estudios acerca de su contenido, forma e influencia. Actas del VII Colloque International Hippocratique, Madrid 1992, pp. 37-53.
} 
Los errores tipográficos son escasos: p. 10, Estagiro; p. 39, n. 84, Kollesh; p. 60, la plantes; p. 93, Balss.

En definitiva, debemos a López Férez un libro bien pensado y resuelto, que sienta las bases de un conocimiento exacto de una de las más controvertidas materias de la fisiología femenina, y que por su procedimiento de análisis es del interés de la medicina, la antropología y la filología.

Jordi REDONDO Universitat de València 